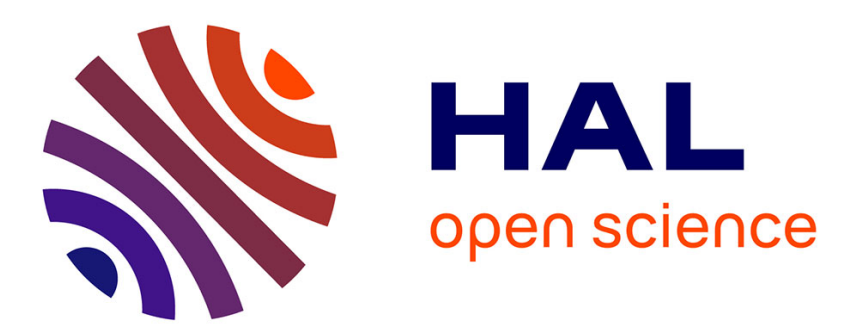

\title{
On-line Monitoring of Nanoparticle Synthesis by Laser-Induced Breakdown Spectroscopy in Vacuum
}

Jessica Picard, Jean-Baptiste Sirven, Olivier Sublemontier

\section{To cite this version:}

Jessica Picard, Jean-Baptiste Sirven, Olivier Sublemontier. On-line Monitoring of Nanoparticle Synthesis by Laser-Induced Breakdown Spectroscopy in Vacuum. MRS Advances, 2016, 2, pp.1487-1491. 10.1557/adv.2016.633 . cea-01445007

\section{HAL Id: cea-01445007 https://hal-cea.archives-ouvertes.fr/cea-01445007}

Submitted on 24 Jan 2017

HAL is a multi-disciplinary open access archive for the deposit and dissemination of scientific research documents, whether they are published or not. The documents may come from teaching and research institutions in France or abroad, or from public or private research centers.
L'archive ouverte pluridisciplinaire HAL, est destinée au dépôt et à la diffusion de documents scientifiques de niveau recherche, publiés ou non, émanant des établissements d'enseignement et de recherche français ou étrangers, des laboratoires publics ou privés. 


\title{
On-line Monitoring of Nanoparticle Synthesis by Laser-Induced Breakdown Spectroscopy in Vacuum
}

Jessica Picard ${ }^{1}$, Jean-Baptiste Sirven ${ }^{2}$, Olivier Sublemontier ${ }^{1}$

${ }^{1}$ NIMBE, CEA, CNRS, Université Paris-Saclay, CEA Saclay, F-91191 Gif sur Yvette cedex, France

${ }^{2}$ DEN - Service d'Etudes Analytiques et de Réactivité des Surfaces (SEARS), CEA, Université Paris-Saclay, F-91191, Gif sur Yvette cedex, France

\begin{abstract}
We propose a new technique suitable for on-line monitoring of gas phase synthesis of nanoparticles. It is based on aerodynamic focusing of nanoparticles followed by Laser-Induced Breakdown Spectroscopy (LIBS) under vacuum. The laser crosses a beam of particles at low pressure so that the plasma-produced photons to be analyzed are emitted only from the particles. Unlike previous experiments, the background from interaction with the gaseous component is totally eliminated from the collected spectra. Vacuum allows also for easier spectra collection in the UV range. Moreover, as the nanoparticle beam is highly collimated, the optical interface windows are not obstructed by particle deposition and the system can be kept running for hours.
\end{abstract}

\section{INTRODUCTION}

Laser-Induced Breakdown Spectroscopy (LIBS) is a widely used method in research for elemental analysis. It allows remote specific detection of most of the chemical elements in a sample and at ppm-level concentrations in solid samples [1]. This technique was already used with nanosized aerosols to probe the chemical composition stability of SiC nanoparticles during their production by laser pyrolysis [2]. However, the background from interaction with the ambient gas reduced dramatically the signal-to-noise ratio in the spectra and even hid some of the signal contributions. Furthermore, unavoidable particle deposition on optical windows at atmospheric pressure is a drag to its use as an efficient technique in continuous-wave mode on high-throughput production plants. Here we propose a new experimental setup for eliminating these difficulties by performing the laser-particle interaction in vacuum.

\section{EXPERIMENTAL DETAILS}

\section{Nanoparticle beam generation}

The principle of the experiment is to cross a beam of isolated nanoparticles with a highly focused laser beam under vacuum conditions and to analyze the plasma-emitted light in the UV and visible range. The experimental arrangement is shown in Figure 1. An Aerodynamic Lens System (ADLS) produces the collimated nanoparticle beam under vacuum from an aerosol stream at atmospheric pressure. This is achieved by carrying the nano-aerosol flow through a 200 
$\mu \mathrm{m}$ limiting entrance orifice followed by a series of four compartments separated by diaphragms. The geometry of the ADLS used in this study is identical to the design proposed by Jayne et al. [3]. It is part of a dedicated multipurpose source chamber available at the PLEIADES beamline at the French national synchrotron radiation facility SOLEIL [4]. This equipment has already been used for nanoparticle studies in the gas phase by interaction with synchrotron radiation [5]. Laser-Induced Breakdown Detection (LIBD) has also been used to probe nanoparticle beam profiles from an ADLS [6]. Beam diameters of less than $100 \mu \mathrm{m}$ were measured with silicon nanoparticles at a distance of $20 \mathrm{~cm}$ from the ADLS outlet. In the ADLS, the trajectories of the nano-aerosols get closer and closer to the axis as they move through the lens and the beam is finally collimated in an expansion vacuum chamber at the ADLS outlet. The nanoparticle beam passes entirely through a $1.5 \mathrm{~mm}$ diameter skimmer and emerges into a high vacuum region before crossing the laser beam. The pressures in the expansion and in the interaction chambers are maintained respectively at around 1 x 10-3 mbar and 1 x 10-6 mbar. The ADLS has been tested with two different sources of nanoparticles. The first one is a commercial setup (Atomizer model 3076, TSI Inc.), which produces a diphasic flow composed of an inert carrier gas and the sample in the aerosol form by atomization of a liquid suspension of nanoparticles. The second alternative nanoparticle source is a laser pyrolysis reactor, in which nanoparticles are synthesized in situ in the gas phase [7]. In this case, a small part of the aerosol stream is sampled and driven to the ADLS.

\section{Laser-induced breakdown spectroscopy}

The excitation source is a Q-switched rod-type fiber laser with an ytterbium-doped photonic crystal fiber as an active gain medium (Boreas, Eolite, France). The laser emits in the infrared $(\lambda=1030 \mathrm{~nm})$ with a nominal pulse width varying from 9 to $20 \mathrm{~ns}$ for repetition rates between 1 and $25 \mathrm{kHz}$, respectively. At the cavity output, the maximum pulse energy is $2 \mathrm{~mJ}$ and the maximum average power is $25 \mathrm{~W}$ with an excellent beam profile $\left(\mathrm{M}^{2}\right.$ close to 1$)$. The laser beam is guided and introduced inside the vacuum chamber using an optical fiber (numerical aperture, N.A. $=0.05$, core diameter $=105 \mu \mathrm{m}$, length $>6 \mathrm{~m}$ ), which ensures a good quality beam allowing suitable irradiances for the plasma formation. The beam is collimated with a $100-\mathrm{mm}$ focal length UV grade lens. A $45^{\circ}$ highly reflective mirror reflects the beam toward a microscope objective (N.A. $=0.25$, effective diameter, E.D. $=15 \mathrm{~mm}$, magnification=10) which focuses the laser beam. Calculations based on Gaussian beams propagation predict a focal diameter of $21.4 \pm$ $2.3 \mu \mathrm{m}$. With this optical configuration, we introduce the effective volume Veff, defined as the portion of the interaction region where the laser irradiance is higher or equal to the breakdown threshold irradiance of a particle. A breakdown threshold irradiance of $5.7 \mathrm{GW} / \mathrm{cm}^{2}$ was previously estimated with similar silicon nanoparticles [6]. This value is quite high compared to what is usually observed for solid targets. This is mainly explained by the particulate nature of the target in our case. In addition, the plasma photon emission duration was measured around $200 \mathrm{~ns}$, compared to several microseconds in the case of experiments at atmospheric pressure. Under these conditions, Laser-Induced Breakdown Detection was used to measure a particlesampling rate of $0.04 \%$ (percentage of laser pulses interacting with a particle). This low value is due to the very small effective volume $\left(3.8 \times 10^{4} \mu \mathrm{m}^{3}\right)$ compared to the number density of the particle beam. It also means that an interaction with more than a single particle is very unlikely [6]. 
The plasma emission is collected with a fused silica optical fiber located at $4 \mathrm{~mm}$ from the plasma, connected to a spectrometer (SP2300i, Acton) equipped with an intensified CCD camera (iStar, Andor) with $2048 * 512$ pixels. The collection of photons under vacuum offers the possibility to work easily in the UV spectral region, allowing for efficient detection of a large number of elements with a large signal to noise ratio.

As the particle beam is very well collimated, no particle deposition was observed on the optical elements during tens of hours.

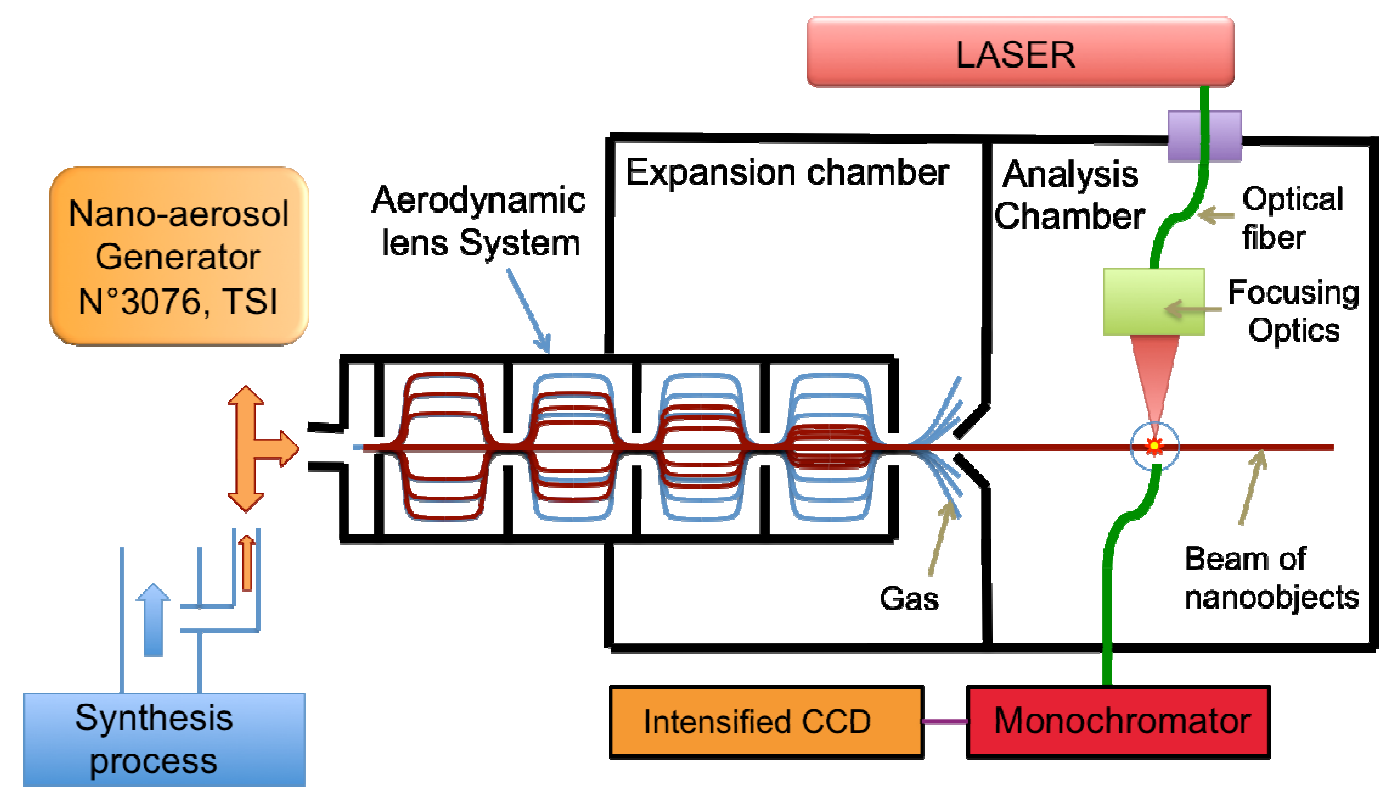

Figure 1. Experimental setup. A collimated beam of nanoparticles is produced by an aerodynamic lens system and crosses a focused laser beam. The plasma-produced photons are collected and analyzed. Either commercial aerosol generators or in situ gas phase synthesis processes are possible.

\section{RESULTS AND DISCUSSION}

The proof of concept is performed with a collimated beam of $80 \mathrm{~nm}$ spherical Silicon nanocrystals. They were first synthesized by laser pyrolysis and further transferred in suspension in pure Ethanol to finally be injected by the commercial aerosol generator. The reason for this choice is only practical. As the particle density is much higher in the case of the in situ synthesis reactor, the commercial aerosol generator is experimentally the less favorable configuration in terms of signal quantity. With a $20 \mathrm{kHz}$ fiber-laser focused in such a way to get at least 10 $\mathrm{GW} / \mathrm{cm}^{2}$ intensity on the particle beam, exploitable spectra are recorded within a few minutes, allowing for continuous-wave or at short time intervals in-process monitoring of particle chemical composition. The spectra shown in Figure 2 are recorded with an average laser power of $10.7 \mathrm{~W}$ at $20 \mathrm{kHz}$, corresponding to a laser irradiance of $11.6 \mathrm{GW} / \mathrm{cm}^{2}$ on the target. The 
global spectrum resulting from the interaction of the laser and the silicon nanoparticles in the UV range between 180 and $320 \mathrm{~nm}$ is shown in Figure 2a. It was obtained using a 600 grooves $/ \mathrm{mm}$ grating. Figures $2 b$ and $2 c$ focus on the $249-255 \mathrm{~nm}$ and $284-292 \mathrm{~nm}$ regions respectively using the same grating but with different software acquisition parameters. The global UV spectrum is relatively noisy, yet typical contributions from silicon atoms are very clearly observed around 250 and $290 \mathrm{~nm}$. Higher resolution spectra shown in Figure $2 \mathrm{~b}$ and $2 \mathrm{c}$ confirm the presence of sensitive Si lines at $250.7 \mathrm{~nm}, 251.4$ and $251.6 \mathrm{~nm}$ (unresolved), and at $288.2 \mathrm{~nm}$. The acquisition proceeds to the addition of individual spectra during $400 \mathrm{~s}$. This duration corresponds to $12 \times 10^{6}$ laser shots. The laser and the detector are not synchronized. It is then estimated that the collected signal in $400 \mathrm{~s}$ corresponds to the effective interaction of about 5000 nanoparticles with the laser. As the laser-particle interaction occurs in the vacuum, the plasma forms, expands and cools very rapidly. This leads to a negligible continuum radiation usually observed in LIBS at atmospheric pressure, which is due to the Bremsstrahlung and radiative recombination phenomena [1]. This justifies the fact that no time-resolved detection was used in this work. In addition, we checked that the spectrum shape under the lines was an instrumental background, since the same acquisition in the absence of nanoparticles yielded exactly the same pattern.

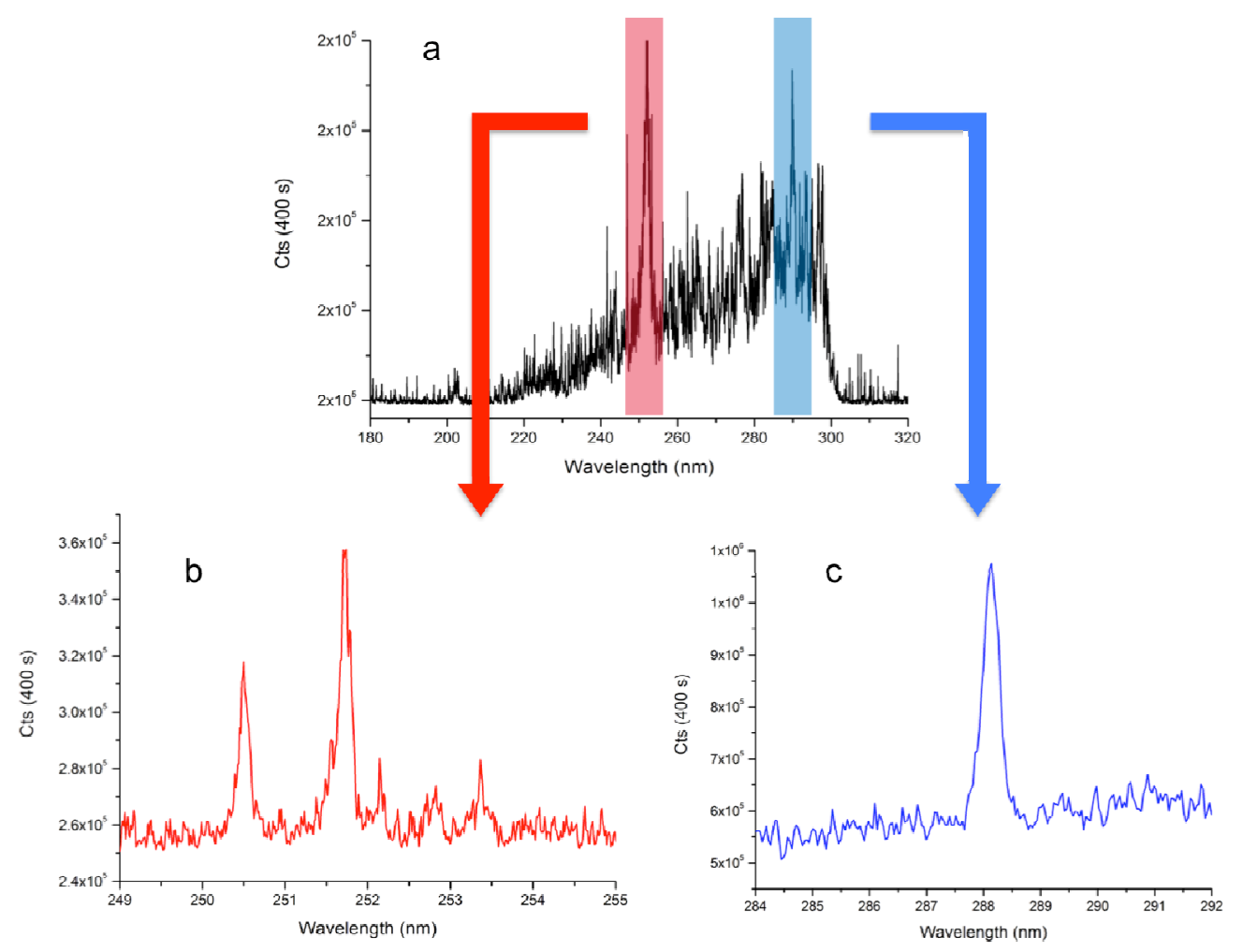

Figure 2. Spectra from silicon nanoparticle. Global UV-range spectrum (a), 249-255 nm-range spectrum (b) and 284-292 nm-range spectrum (c). Lines from silicon element are clearly observed. 


\section{CONCLUSION}

We have demonstrated the feasibility of on-line monitoring of nanoparticle elemental chemical analysis by LIBS under vacuum. The setup includes an aerodynamic lens to produce a dense and collimated beam of nanoparticles on which the laser is focused. The proof of concept is performed with $80 \mathrm{~nm}$ silicon nanoparticles previously synthesized by laser pyrolysis and injected with a commercial aerosol generator. Spectra showed exploitable silicon lines in the UV range within a few minutes acquisition time that allows for real time monitoring.

\section{ACKNOWLEDGMENTS}

The authors would like to thank John Bozek and the PLEIADES beamline team for their precious technical help and for the provision of the Multi-Purpose Source Chamber at SOLEIL synchrotron facility.

\section{REFERENCES}

1. A. W. Miziolek, V. Palleschi, I. Scheschter, Laser-induced breakdown spectroscopy (LIBS). Fundamentals and applications (Cambridge University Press, Cambridge, 2006).

2. T. Amodeo, C. Dutouquet, F. Tenegal, B. Guizard, H. Maskrot, O. Le Bihan, E. Fréjafon, Spectrochim. Acta Part B At. Spectrosc. 63 (2008) 1183-1190. doi:10.1016/j.sab.2008.09.005.

3. J.T. Jayne, D.C. Leard, X. Zhang, P. Davidovits, K.A. Smith, C.E. Kolb, D.R. Worsnop, Aerosol Sci. Technol. 33 (2000) 37-41.

4. A. Lindblad, J. Söderström, C. Nicolas, E. Robert, C. Miron, Rev. Sci. Instrum. 84 (2013) 113105. doi:10.1063/1.4829718

5. O. Sublemontier, C. Nicolas, D. Aureau, M. Patanen, H. Kintz, X. Liu, M.-A. Gaveau, J.L. Le Garrec, E. Robert, F.-A. Barreda, A. Etcheberry, C. Reynaud, J.B. Mitchell, C. Miron, J. Phys. Chem. Lett. 5 (2014) 3399-3403. doi:10.1021/jz501532c.

6. F.-A. Barreda, C. Nicolas, J.-B. Sirven, F.-X. Ouf, J.-L. Lacour, E. Robert, S. Benkoula, J. Yon, C. Miron, O. Sublemontier, Sci. Rep. 5 (2015) 15696. doi:10.1038/srep15696.

7. O. Sublemontier, H. Kintz, F. Lacour, Kona Powder Particle J. 29 (2011) 236-250. 